Volume 8. No. 10, October 2020

International Journal of Emerging Trends in Engineering Research

Available Online at http://www.warse.org/IJETER/static/pdf/file/ijeter508102020.pdf

https://doi.org/10.30534/ijeter/2020/508102020

\title{
Use of an unmanned aerial vehicle in order to increase the intelligence capabilities of divisions
}

\author{
Daulet Toibazarov $^{1}$, Kuandyk Akshulakov ${ }^{2}$, Sandybek Tynybayev ${ }^{3}$, Yerlan Kairov ${ }^{4}$, Dauren Kassenov ${ }^{5}$ \\ ${ }^{1}$ National University of Defense of the First President of the Republic of Kazakhstan - Elbasy, Nur-Sultan, \\ Kazakhstan,dtoibazarov@inbox.ru \\ ${ }^{2}$ National University of Defense of the First President of the Republic of Kazakhstan - Elbasy, Nur-Sultan, \\ Kazakhstan, kuandyk.akshulakov@bk.ru \\ ${ }^{3}$ National University of Defense of the First President of the Republic of Kazakhstan - Elbasy, Nur-Sultan, \\ Kazakhstan, sandybek.tynybayev@bk.ru \\ ${ }^{4}$ National University of Defense of the First President of the Republic of Kazakhstan - Elbasy, Nur-Sultan, \\ Kazakhstan, yerlan.kairov@bk.ru \\ ${ }^{5}$ Department of military education and science of the Ministry of defense of the Republic of Kazakhstan, \\ Nur-Sultan, Kazakhstan, dauren.kassenov@bk.ru
}

\begin{abstract}
This article deals with topical issues of increasing the capabilities, modernizing the combat potential, forces and means of intelligence by introducing unmanned aerial vehicles. Examples of tactically and technically effective models of unmanned aerial vehicles, their advantages and calculations of increasing the probability of detecting an enemy object are given.
\end{abstract}

Key words : Forces and means of intelligence, technical means of intelligence, unmanned aerial vehicle, aerial reconnaissance, enemy object.

\section{INTRODUCTION}

The military-political situation in the world is characterized by high dynamics and unpredictability of development, increased confrontation between world and regional "powers" for spheres of influence in the world, as well as the increasing role of military force in resolving inter-state and intra-state contradictions. The combination of the armed forces, other troops and military formations, state bodies and organizations, and the military-industrial complex, whose joint activities are aimed at ensuring military security and defense of the country indicates the effectiveness of the military organization of the state. Intensive development of information technologies and the digital market allows increasing the combat and strategic potential of weapons[1]. Against the background of a sharp increase in the combat effectiveness of weapons, especially high-precision weapons, increasing the speed and dynamism of modern combat and operations, there is a need to develop the quality parameters of the army, combat characteristics of equipment and weapons, organizational and staff structure, training of headquarters and troops, the use of modern intelligence tools to timely identify the intentions of a likely enemy both in the initial period of military operations and during their conduct [2]. One of the solutions to this problem is the introduction of unmanned aerial vehicles( UAVs), advanced information technologies in the process of conducting intelligence, which will allow commanders of land forces formations at all levels to more clearly present the overall picture of the fighting, which will provide a better understanding of the current situation at all levels.

Unmanned aerial vehicles have become an integral part of modern warfare. They are used for conducting reconnaissance, targeting high-precision weapons, electronic warfare, and can themselves be shock weapons.

Currently, the armed forces of 41 countries operate about 80 models of UAVs.

What is the UAV complex? The UAV complex is a set of interconnected UAVs and ground-based technical means that ensure its combat use in the air and technical operation on the ground. Its composition can vary widely depending on the tasks to be solved, the objects of action, the conditions of use, the size of the UAV, etc. In General, this is a transport launcher designed to deliver the UAV to the starting position and launch it; transport and charging machine that picks up the UAV after landing, delivering it to the technical position and the starting unit; technological machine to prepare the UAV for use. Depending on the intended purpose, the complex can be supplemented with other technical means for shock purposes, intelligence - ground means of checking various onboard equipment, as well as receiving and processing information [5].

The analysis of the achieved level of development of UAVs, as well as the experience of their combat use, allowed us to identify the strengths of UAVs: 
compact and lightweight, which allows you to carry complexes with UAVS directly by members of the reconnaissance group as a combat duffel bag;

low cost compared to manned aircraft;

the ability to stay over a given area for a long time, collecting information about the enemy and transmitting it in a time scale close to real, both to ground control centers, and indirectly to the crews of aircraft and helicopters of strike aircraft in the air, the ability to conduct surveillance at low altitude from different directions, which allows you to get a detailed image of objects in various angles and their shadows depending on the sun's illumination;

high mobility of UAV complexes, which can be quickly transferred to any region in special containers, and mobile control points can be placed in advance in points of forward basing in the immediate vicinity of the areas of their combat use;

cross-border operation of UAVs due to their ability to penetrate deep into the territory;

elimination of losses of crews of manned aircraft with greater efficiency of performing tasks by UAVs than by manned aviation, since UAVs can perform tasks in the deep rear of the enemy to investigate and defeat well-protected objects, which it is considered a difficult task for manned aircraft [6].

The "UAV" factor excludes not only human losses, but also reduces the weight of the aircraft and its size, increases the share of the payload.

The absence of a crew on Board the aircraft allows you to plan more complex and more risky combat tasks, during which you have to approach the object at a minimum distance, and sometimes even make a RAM.

These features of complexes with UAVs make it necessary to implement them and equip them with reconnaissance units and formations to solve a wide range of tasks, including for conducting all types of aerial reconnaissance and electronic warfare [7].

For example, we can consider the most widely distributed mini-UAV aircraft scheme, which includes the UAV RQ-11 " Raven "(Fig.1) and RQ-J4" DragonEye " (Fig.2).

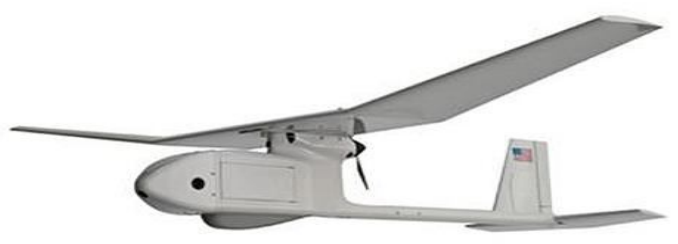

Figure 1: RQ-11 «Raven»

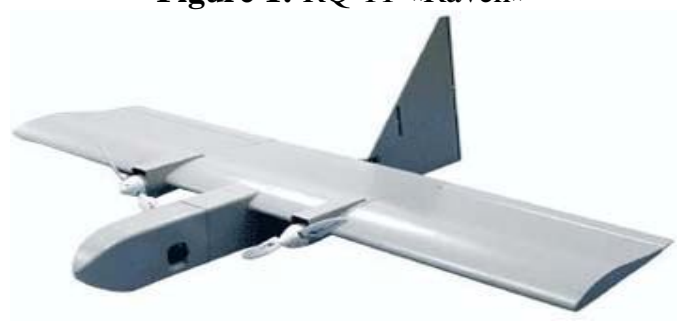

Figure 2: RQ-J4 «DragonEye»
These UAVs equipped with a television and / or thermal imaging camera can be included in the regular weapons of tactical units (from the company and below). If necessary, the flight commander, using UAVs of this category, will be able to quickly get information about the enemy and the situation, which is most critical when conducting a battle in difficult conditions, such as in populated areas. This will allow you to effectively manage the actions of the unit and reduce losses [8].

The UAV's tactical and technical characteristics play an important role in achieving effective results. Information on the considered instances of "UAVs" is shown in table 1.

Table 1: Tactical and technical characteristics of the UAV RQ-11 «Raven» andRQ-14 «Dragon Eye»

\begin{tabular}{|c|c|c|}
\hline Name & «Raven» & «DragonEye \\
\hline $\begin{array}{l}\text { Weight, kg: } \\
\text { maximum take-off speed } \\
\text { payload }\end{array}$ & $\begin{array}{l}2,3 \\
0,18\end{array}$ & $\begin{array}{l}1,8 \\
0,1\end{array}$ \\
\hline The radius of action, $\mathrm{km}$ & 10 & 10 \\
\hline $\begin{array}{l}\text { Maximum flight speed, km } \\
\text { / h }\end{array}$ & 64 & 73 \\
\hline The flight duration, min. & 90 & 40 \\
\hline $\begin{array}{l}\text { The geometric dimensions, } \\
\mathrm{m} \text { : } \\
\text { wingspan } \\
\text { the length of the fuselage }\end{array}$ & $\begin{array}{l}\text { L33 } \\
0,9\end{array}$ & $\begin{array}{l}0,95 \\
1,1\end{array}$ \\
\hline
\end{tabular}

Another project that deserves attention is the unmanned system based on the RQ-16 mini-UAV vertical takeoff and landing

"T-Hawk "by Honeywell. It is considered as a means of intelligence support for the actions of units in the platoon/company link. The device, made according to the "screw in the ring" scheme, as well as a compact ground control station are placed in special containers and can be carried by a single soldier ( Fig.3 and Fig. 4).

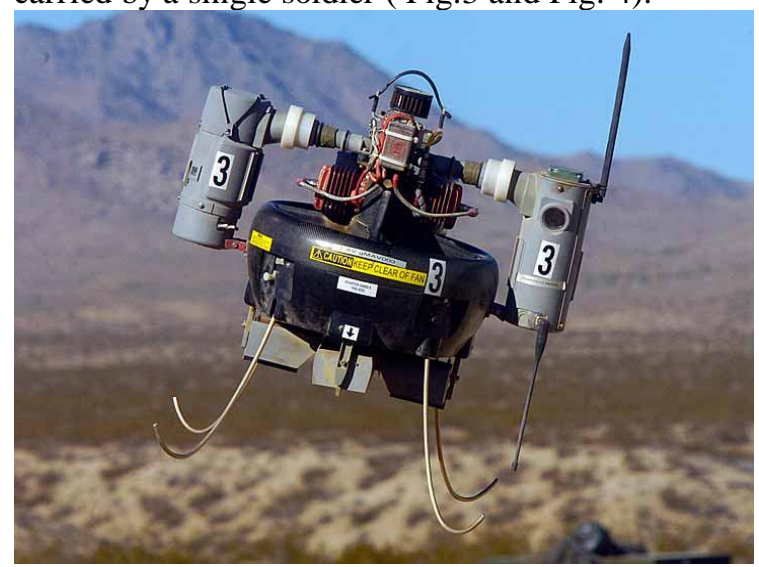

Figure 3: RQ-16 «T-Hawk» 


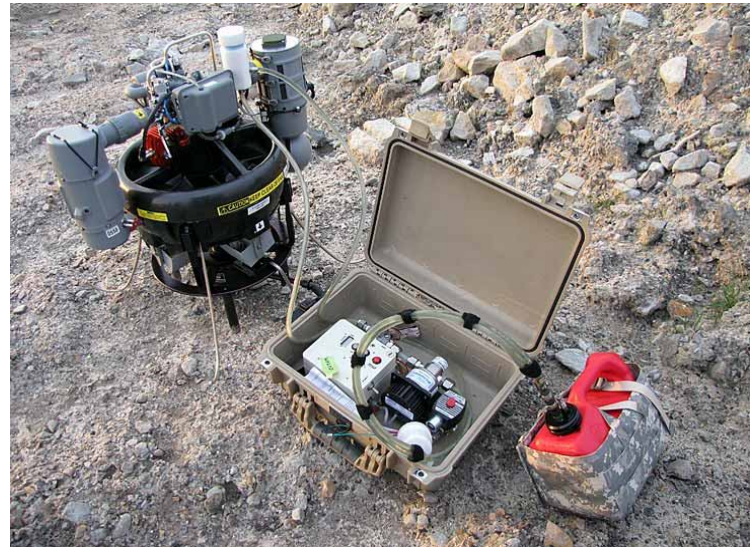

Figure 4: -UAV stationRQ-16 «T-Hawk»

The onboard equipment of the UAV, which is placed in two cylindrical fairings, includes the control system of the device, the NAVSTAR KRNS receiver, television and infrared cameras, as well as equipment for transmitting intelligence information at a range of up to $10 \mathrm{~km}$.

The system passed successful military tests on the territory of the United States, during which, in particular, the possibility of transmitting video images from the UAV to the an-64 Apache attack helicopter was tested. Due to the high level of automation, the machine is easy to operate, and the operator training time for its operation is about 16 hours. [8, p. 50] the Main tactical and technical characteristics of the RQ-16 "T-Hawk" UAV are shown in table 2.

Table 2: Tactical and technical characteristics of the UAVRQ-16 «T-Hawk»

\begin{tabular}{|l|l|}
\hline Name & indicators \\
\hline Maximum take-off weight, $\mathrm{kg}$ & 8,4 \\
\hline Maximum range, $\mathrm{km}$ & 8 \\
\hline Maximum flight duration, min & 45 \\
\hline Geometric dimensions, $\mathrm{mm}:$ & \\
Outer diameter of the case & 350 \\
The diameter of the screw & 280 \\
height & 560 \\
\hline
\end{tabular}

Operators of helicopter weapons equipped with unified control equipment for army drones will be able to set the UAV flight route, the mode of operation of intelligence systems, and in the future - to issue target designation and commands for the use of their onboard weapons.

In order to ensure that intelligence from unmanned vehicles can be transmitted directly to strike vehicles and ground unit commanders, remote video information reception terminals are being developed. In General, the analysis of the experience of using unmanned systems of various classes by the armed forces of different countries confirms the high efficiency of this type of weapon in the conditions of modern military operations of any intensity. According to military experts, the number of UAVs in the troops, as well as the range of tasks they solve, will steadily increase.

The inclusion of unmanned systems in the composition of intelligence units and formations will significantly increase the effectiveness of intelligence and provide the commander and staff with more extensive intelligence information.

Using the formula for calculating the probability of opening an enemy object with the addition of an additional intelligence Agency (UAV), you can check the increase in the probability of enemy objects:

$\mathrm{P}=1$ - ((1 - P1) * (1-P2)*(1-RZ)*(1-P4)).

Where:

- P1 is the probability of opening of ORD;

- P2-probability of opening the BRD;

- RZ-probability of opening the inventory item;

- P4-probability of opening the UAV.

$\mathrm{P} .=1-((1-0,5) *(1-0,5) *(1-0,3) *(1-1))$.

$\mathrm{P}=1$.

\section{CONCLUSION}

Thus, with the introduction of UAV units into the intelligence units, the capabilities of the forces and means of intelligence significantly increase, which, in turn, allows the commander and staff to have more extensive information, to organize air reconnaissance in real time in the interests of combined arms units. Received information from the UAV in real time 6-8 minutes, this helps the commander to make a timely decision on fire damage, as well as planning other events.

Analyzing the tasks that can be implemented through the introduction of unmanned aerial vehicles into the number of forces and means of reconnaissance, a high potential of this direction is observed. Based on the requirements of the Military doctrine of the Republic of Kazakhstan, defining the main directions of state activity in military-political, military-strategic and military-economic sphere, for mobilization training of the state, as well as the basic measures for the development of the military organization of the Republic of Kazakhstan, implementation of upgrades in the form of a UAV does not contravene them.

\section{ACKNOWLEDGEMENT}

The authors are very grateful to the Ministry of education and Science of the Republic of Kazakhstan for providing financial assistance in conducting this research.

\section{REFERENCES}

1.Watts, A.C.; Ambrosia, V.G.; Hinkley, E.A. Unmanned aircraft systems in remote sensing and scientific research: Classification and considerations of use. Remote Sens. 2012, 4, 1671-1692.

2. Dalamagkidis, K. "UAV Applications" in Handbook of Unmanned Aerial Vehicles; Springer: Berlin/Heidelberg, Germany, 2015; pp. 2639-2860.

3. Salamí, E.; Barrado, C.; Pastor, E. UAV flight experiments applied to the remote sensing of vegetated areas. Remote Sens. 2014, 6, 11051-11081.

4. Whitehead, K.; Hugenholtz, C.H. Remote sensing of the environment with small unmanned aircraft systems 
Daulet Toibazarov et al., International Journal of Emerging Trends in Engineering Research, 8(10), October 2020, 6929 - 6933

(UASs), part 1: A review of progress and challenges. J. Unmanned Veh. Syst. 2014, 2, 69-85.

5. Gonzalez, L.F.; Montes, G.A.; Puig, E.; Johnson, S.; Mengersen, K.; Gaston, K.J. Unmanned aerial vehicles (UAVs) and artificial intelligence revolutionizing wildlife monitoring and conservation. Sensors 2016, 16, 97.

6. Achille, C.; Adami, A.; Chiarini, S.; Cremonesi, S.; Fassi,

F.; Fregonese, L.; Taffurelli, L. UAV-based photogrammetry and integrated technologies for architectural applications-Methodological strategies for the after-quake survey of vertical structures in Mantua (Italy). Sensors 2015, 15, 15520-15539.

7. Bhardwaj, A.; Sam, L.; Bhardwaj, A.; Martín-Torres, F.J. LiDAR remote sensing of the cryosphere: Present applications and future prospects. Remote Sens. Environ. 2016, 177, 125-143.

8. Royo, P.; Pastor, E.; Barrado, C.; Cuadrado, R.; Barrao, F.; Garcia, A. Hardware Design of a Small UAS Helicopter for Remote Sensing Operations. Drones 2017, 1, 3.

9. Royo, P.; Barrado, C.; Cuadrado, R.; Pastor, E.; Barrao, F.; Garcia, A. Development of a small UAS helicopter for remote sensing operations. In Proceedings of the 2016 IEEE/AIAA 35th Digital Avionics Systems Conference (DASC), Sacramento, CA, USA, 25-29 September 2016; pp. $1-25$.

10. MacFarlane, J.W.; Payton, O.D.; Keatley, A.C.; Scott, G.P.; Pullin, H.; Crane, R.A.; Smilion, M.; Popescu, I.; Curlea, V.; Scott, T.B. Lightweight aerial vehicles for monitoring, assessment and mapping of radiation anomalies. J. Environ. Radioact. 2014, 136, 127-130.

11. Martin, P.G.; Payton, O.D.; Fardoulis, J.S.; Richards, D.A.; Scott, T.B. The use of unmanned aerial systems for the mapping of legacy uranium mines. J. Environ. Radioact. 2015, 143, 135-140.

12. Martin, P.G.; Payton, O.D.; Fardoulis, J.S.; Richards, D.A.; Yamashiki, Y.; Scott, T.B. Low altitude unmanned aerial vehicle for characterising remediation effectiveness following the FDNPP accident. J. Environ. Radioact. 2016, 151, 58-63.

13. Martin, P.G.; Kwong, S.; Smith, N.T.; Yamashiki, Y.; Payton, O.D.; Russell-Pavier, F.S.; Fardoulis, J.S.; Richards, D.A.; Scott, T.B. 3D unmanned aerial vehicle radiation mapping for assessing contaminant distribution and mobility. Int. J. Appl. Earth Obs. Geoinf. 2016, 52, 12-19. 14. Martin, P.G.; Moore, J.; Fardoulis, J.S.; Payton, O.D.; Scott, T.B. Radiological assessment on interest areas on the sellafield nuclear site via unmanned aerial vehicle. Remote Sens. 2016, 8, 913.

15. Aleotti, J.; Micconi, G.; Caselli, S.; Benassi, G.; Zambelli, N.; Calestani, D.; Zanichelli, M.; Bettelli, M.; Zappettini, A. Unmanned aerial vehicle equipped with spectroscopic CdZnTe detector for detection and identification of radiological and nuclear material. In Proceedings of the 2015 IEEE Nuclear Science Symposium and Medical Imaging Conference (NSS/MIC), San Diego, CA, USA, 31 October-7 November 2015; pp. 1-5.
16. Cai, C.; Carter, B.; Srivastava, M.; Tsung, J.; Vahedi-Faridi, J.;Wiley, C. Designing a radiation sensing UAV system. In Proceedings of the 2016 IEEE Systems and Information Engineering Design Symposium (SIEDS), Charlottesville, VA, USA, 29-29 April 2016; pp. 165-169.

17. Behnke, D.; Rohde, S.;Wietfeld, C. Design and experimental validation of $\mathrm{UAV}$-assisted radiological and nuclear sensing. In Proceedings of the 2016 IEEE Symposium on Technologies for Homeland Security (HST), Waltham, MA, USA, 10-11 May 2016; pp. 1-6.

18. Li, B.; Zhu, Y.;Wang, Z.; Li, C.; Peng, Z.R.; Ge, L. Use of multi-rotor unmanned aerial vehicles for radioactive source search. Remote Sens. 2018, 10, 728.

19. Royo, P.; Perez-Batlle, M.; Cuadrado, R.; Pastor, E. Enabling dynamic parametric scans for unmanned aircraft system remote sensing missions. J. Aircr. 2014, 51, 870-882.

20. mRo Pixhawk Flight Controller (Pixhawk 1). Available online:

https://docs.px4.io/en/flight_controller/mro_pixhawk.html (accessed on 10 September 2018).

21. Meier, L.; Tanskanen, P.; Heng, L.; Lee, G.H.; Fraundorfer, F.; Pollefeys, M. PIXHAWK: A Micro Aerial Vehicle Design for Autonomous Flight Using Onboard Computer Vision. Auton. Robots 2012, 33, 21-39. [CrossRef]

22. PX4 Flight Stack. Available online: http://px4.io/ (accessed on 10 September 2018).

23. Ardupilot Flight Stack. Available online: http://ardupilot.org/copter/ (accessed on 10 September 2018). 24. SF11/C $(120 \mathrm{~m})$ Lightware Laser Altimeter. Available online: $\quad$ https://lightware.co.za/products/sf11-c-120-m (accessed on 10 September 2018).

25. Mission Planner Overview. Available online: http://ardupilot.org/planner/docs/mission-planner-overview. html (accessed on 10 September 2018).

26. Raspberrry $\mathrm{Pi} 3$ Model $\mathrm{B}+$. Available online: https://www.raspberrypi.org/products/raspberry-pi-3-modelb - plus/ (accessed on 10 September 2018).

27. RITEC Radiation Micro Spectrometer uSPEC. Available online: http://www.ritec.lv/uspec.html (accessed on 10 September 2018).

28. DJI F550 ARF. Available online: https://www.dji.com/es/flame-wheel-arf (accessed on 11 September 2018).

29. Gilmore, G. Practical Gamma-Ray Spectroscopy; John Wiley \& Sons Ltd.: West Sussex, UK, 2008.

30. International Atomic Energy Agency (IAEA). Safety of Radiation Sources: International Basic Safety Standards, General Safety Requirements, IAEA Safety Standards Series No. GSR Part 3; IAEA Publications: Vienna, Austria, 2014.

31. Sempau, J.; Badal, A.; Brualla, L. A PENELOPE-based system for the automated Monte Carlo simulation of clinacs and voxelized geometries-Application to far-from-axis fields. Med. Phys. 2011, 38, 5887-5895. 
32. Gasull, M.; Royo, P.; Cuadrado, R. Design a RPAS

Software Architecture over DDS. Master's Thesis, Castelldefels School of Telecommunications and Aerospace Engineering, Castelldefels, Spain, 2016.

33. Garro Fernandez, J.M. Drone Configuration for Seaside Rescue Missions. Master's Thesis, Universitat Politècnica de Catalunya, Barcelona, Spain, 2017.

34. Macias, M. Study of 4G Propagation Conditions Using Unmanned Aerial Systems. Ph.D. Thesis, Universitat Politècnica de Catalunya, Barcelona, Spain, 2018.

35. Cloud Cap Technology. Piccolo II Product. 2017. Available online: http://www.cloudcaptech.com/products/ detail/piccolo-ii (accessed on 7 July 2017).

36. Makangali, K. Konysbaeva, D.; Zhakupova, G.; Gorbulya, V.; Suyundikova, Zh. Study of sea buckthorn seed powder effect on the production of cooked-smoked meat products from camel meat and beef. Periodico Tche Quimica, 2019, 16: 130-139.

37. Lisitsyn A., Makangali K., Uzakov Y., Taeva A., Konysbaeva D., Gorbulya, V (2018) Study of the National Cooked Smoked Meat Products While Tests with Laboratory Animals at the Pathology Models with the Purpose to Confirm the set of Biocorrective Features. Current Research in Nutrition and Food Science journal 6(2): 536-551.

38. Guava EventBus. Available online: https://github.com/google/guava/wiki/EventBusExplained (accessed on 12 September 2018).

39. Message Queuing Telemetry Transport (MQTT). Available online: http://mqtt.org/ (accessed on 12 September 2018).

40. MAVLink Micro Air Vehicle Communication Protocol. Available online: http://qgroundcontrol.org/ mavlink/start (accessed on 12 September 2018).

41. Hibernate. Available online: http://hibernate.org/ (accessed on 12 September 2018).

42. H2 Database Engine. Available online: http://www.h2database.com/html/main.html (accessed on 12 September 2018).

43. European Accreditation. EA-4/02 M: 2013 Evaluation of the Uncertainty of Measurement in Calibration. 2013. p. 75. 